\title{
Morphometric characteristics of craniofacial features in patients with schizophrenia
}

\author{
Mesbah Fakhroddin PhD1, Ghanizadeh Ahmad MD³, Shah Imran GP', \\ ${ }^{1}$ Department of Anatomical Sciences, School of Medicine, Shiraz University of Medical Sciences, Shiraz, Iran \\ ${ }^{2}$ ER resident, Hussein Al Ali Hospital, Saudi Arabia \\ ${ }^{3}$ Reasech Center for Psychiatry and Behavioral Sciences, Department of Psychiatry, School of Medicine, Shiraz University of Medical \\ Sciences, Shiraz, Iran
}

\section{Abstract}

Background: High incidence of craniofacial dysmorphology in patients with schizophrenia confirms the developmental disruptions during embryonic period. Anthropometry of head and face can give us several clues regarding the maldevelopment of brain. The aim of this study was to assess various dimensions of skull in Schizophrenics. Methods: One hundred and one (101) male and female patients that have been diagnosed with chronic schizophrenia were selected from a psychiatric hospital and 101 healthy controls, which were mostly the paramedical staff of another hospital, were included in the study. The age for both the groups was between 20 to 60 years. The head length, width and height and coronal, axial and sagittal arc lengths, and also body height and weight and BMI of participants were measured. Results: Mean anthropometric measurements of head length, width and height were 18.92, 14.08 and 12.69 in patients and 18.90, 13.89 and 13.38 centimeter in control, also axial, coronal and sagittal arc lengths were 55.85, 35.21 and 33.00 in patients and 55.70, 34.54 and 32.19 centimeter in control group, respectively. Compared to controls the patients had significantly increased coronal ( $\mathrm{P}<0.022)$ and Sagittal $(P<0.001)$ arc lengths. The patients also showed significantly lesser head height $(P<0.001)$ as compared with controls. Conclusion: The linear measurements of skull in patients with Schizophrenia do not significantly differ from normal populations and/or have slightly differences. Future studies may investigate whether head can be an anatomical marker for patients with schizophrenia.
\end{abstract}

Keywords: Anthropometry; Craniofacial; Morphogenesis; Schizophrenia

Received date: $25-11-2013$

Accepted date: $30-01-2014$

doi: http://dx.doi.org/10.4172/Psychiatry.1000107

\section{Introduction}

Schizophrenia is a mental disorder that is seen in acute and chronic form which can lead to social problems and long-term disability. Despite differences in geographic, social and cultural backgrounds, about one ten thousandth of young population (15-35 years) in the world is affected by this disorder each year. Thereby, one percent of the populations (15-60 years) in the world are suffering from schizophrenia ${ }^{1-5}$.

So far, the etiology of schizophrenia is not known clearly yet, but the interplay of genetic, environmental and social factors are believed to be involved. There is much evidence indicated that disturbed prenatal development significantly increases the risk of schizophrenia ${ }^{6,7}$. These observations have been confirmed by many studies. According to current literature, the adults suffering from schizophrenia have several physical malformations, especially in the craniofacial region. Most fetal disorders occur in the first and second trimester of embryonic development ${ }^{8-12}$. In initial stages of embryogenesis, there is a very close relationship between

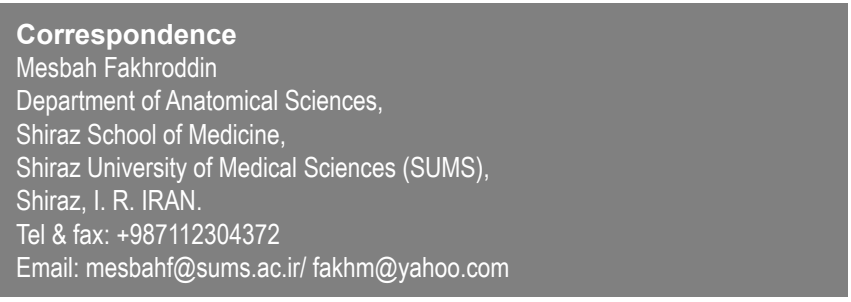

the craniofacial development and ventral portion of brain; therefore, maldevelopment in one predisposes the other for malformation ${ }^{11,13}$. Also, there is scientific evidence to show the important relationship between cleft lip and palate and brain development ${ }^{14,15}$. Anthropometric analysis also shows the presence of maldevelopment of the middle portion of skull in patients with schizophrenia ${ }^{6,11,16}$.

Nonetheless, the biology of brain development is not properly understood, but as biology of facial development is completely clear, it can be used to understand the morphogenesis of brain ${ }^{11}$. Facial deformity can be used as a valuable index to trace the abnormalities of brain development. ${ }^{17}$ It has also reported that, the craniofacial dysmorphogenesis and schizophrenia are associated with Velocardiofacial syndrome ${ }^{18,19}$. The morphological relationship between the face and brain should not only be studied over anatomical or embryonic basis, but should be also done at the level of brain function ${ }^{17}$.

Schizophrenia is a complex and unique disease ${ }^{20}$, therefore many hypotheses have been postulated regarding the factors and causes that are responsible for schizophrenia. These hypotheses have different assumptions, some based on environment, genetics, social or biological backgrounds ${ }^{21}$. Among all, neurodegeneration and neurodevelopmental hypotheses are more accepted. In the past two decades neurodevelopmental hypothesis has been paid more attention ${ }^{20}$. According to this hypothesis, the schizophrenia may be as a result of some primary damages to the brain during prenatal or postnatal period which leads 
to maldevelopment in its maturity. These damages can have different backgrounds like genetic, embryonic and even during delivery ${ }^{21}$. Neurodevelopmental hypothesis is also based on the studies of cerebral cortex. Neuropathologic studies in patients with schizophrenia show changes in the structure of the brain, which may result in miss size, misplace and disorganize of cortical neurons in second trimester of fetal development ${ }^{22-26}$. The lack of gliosis in the brain shows that schizophrenia is not a result of neurodegeneration, but as a result of the damage of neurons caused before the $20^{\text {th }}$ week of embryogenesis ${ }^{27}$. Reduced grey matter volume has also been reported in patients with schizophrenia undergoing $\mathrm{MR}^{28}$.

The neurodevelopmental hypothesis is further confirmed by the presence of neuralcelladhesion molecules and growthassociated protein- 43 in the brains of patients suffering from schizophrenia ${ }^{29,30}$. Abnormal sulci and gyri which present in the brain of postmortem patients with schizophrenia confirm the possibility of maldevelopment of brain, because the sulci and gyri are developed during 16-29th weeks of fetal life ${ }^{31-}$ ${ }^{33}$. High incidence of craniofacial malformation in patients with Schizophrenia also confirms neurodevelopmental hypothesis, in particular dysmorphology which present in the structures with ectodermal origin ${ }^{34}$. The thalamus of the rhesus monkeys exposed to radiations, were later found to present with dysmorphogenesis of face ${ }^{35}$. Craniofacial anthropometry can be very useful indexes to further support the neurodevelopmental hypothesis of craniofacial dysmorphology in patients with schizophrenia ${ }^{36}$. The aim of this study was to assess various dimensions of skull in the patients with schizophrenia and compare them with general population.

\section{Methods}

\section{Subjects}

Participants in this study, 101 male and female in patients with chronic schizophrenia (based on DSM-IV criteria) were selected from a psychiatric hospital and 101 healthy male and female volunteers, mainly the staff of teaching hospitals of Shiraz Medical School were recruited as a control group. All of the participants were between $20-60$ years of age. The participants were excluded if they had any history of skull fractures or any other diseases that could had influenced their skull size.

\section{Techniques}

According to the study of Peter F Buckley et al (2002), ${ }^{35}$ the following cranial dimensions were measured in each individual:

a- Head length: Projective distance from glabella to opsithocranion (the point in the occipital region most distant to glabella).

b- Head width: Projective distance between the both tragions.

c- Head height: Perpendicular distance from the Frankfurt horizontal plane to the vertex (in addition to the study of Buckley).

d- Axial arc length: Head circumference.

e- Coronal arc length: Arc length between the both tragions, through the vertex.

f- Sagittal arc length: Arc length between glabella and opsithocranion, through the vertex (in addition to the study of Buckley).

Head length and head width were measured using a head and neck stainless steel $45 \mathrm{~cm}$ caliper. To further enhance the accuracy, the reading from the head and neck stainless steel caliper was again measured by a digital sliding caliper (Mutitoya 193 digital calipers, Japan). Head height was measured using a centimeter/millimeter scale.Axial, coronal and sagittal arc lengths were measured by an anatomical tape measure (Seca S201 anatomical tape measure-ses007). To ensure further accuracy the measurements were done by two individuals, one of which was unaware of the diagnosis. We spent as much as necessary time for each individual to make the accuracy measurement.

Body height and weight and BMI of patients and normal subjects were also measured by a digital scale (Seca professional digital column scale). This study was approved by the ethical committee of SUMS (Shiraz University of Medical Sciences). The statistical analysis for this study was conducted using SPSS Inc. USA, 15 Software.

\section{Results}

Out of 101 patients with schizophrenia, 68 were males and 33 were females. The mean ( \pm SD) age in the patient group was $44.02( \pm 9.50)$ years. Among the control population, there were 51 females and 50 males. The mean ( \pm SD) age in this group was $30.86( \pm 6.68)$ years. The parameters of age, weight, height and body mass index of both the groups with their respective mean, maximum, minimum and standard deviation are shown in Table 1.

The statistical analysis of sex ratio and the age between the two groups were significantly differences, with $P<.001$ for sex ratio using chi-square and $P<.010$ for age using t- test. Since this statistical significance probably had influenced our results, the six cranial measurements were compared and calculated using univariate analysis of variance taking

\begin{tabular}{|c|c|c|c|c|c|}
\hline & Group & Minimum & Maximum & Mean & Std. deviation \\
\hline \multirow{2}{*}{ Age (years) } & 1 & 24 & 60 & $44.02^{*}$ & 9.50 \\
\hline & 2 & 22 & 48 & 30.86 & 6.68 \\
\hline \multirow{2}{*}{ Weight (kilograms) } & 1 & 40 & 96.4 & 66.46 & 13.22 \\
\hline & 2 & 41.5 & 100.3 & 65.87 & 14.45 \\
\hline \multirow{2}{*}{ Height (centimeters) } & 1 & 103 & 185 & 162.79 & 11.58 \\
\hline & 2 & 139.5 & 187 & 164.45 & 9.60 \\
\hline \multirow{2}{*}{ Body mass index } & 1 & 13.6 & 38.2 & 24.64 & 4.67 \\
\hline & 2 & 16.2 & 36.3 & 24.24 & 4.17 \\
\hline
\end{tabular}


age and sex as covariate, therefore, omitting their influence, if any, over the results. Compared to controls the patients with schizophrenia had significantly increased coronal and sagittal arc lengths with $P<0.022 \& P<0.001$ respectively (Tables 2). In the patient group, the mean of coronal arc length was $35.22 \mathrm{~cm}$ and the mean of sagittal arc length was $33.01 \mathrm{~cm}$, and their respective standard deviations were 2.58 $\& 1.81$. The patients also showed significantly lesser head height as compared to control group $(P<0.001)$ (Table 2$)$. The mean head height in patient group was $12.70 \mathrm{~cm}$ with a standard deviation of 0.73 . For all participants, there were no statistical significant differences for the other three cranial measurements which include head length $(P<0.790)$, head width $(P<0.650)$ and axial arc length $(P<0.719)$. The mean and the standard deviation of all the six cranial measurements in both groups (patients \& controls) are depicted in Table 2.

\section{Discussion}

Two hypotheses have been proposed for the etiology of schizophrenia, one is based on the factors affecting primary and secondary brain development "early and late neurodevelopment" and the second is based on brain regression "neurodegeneration". In the past two decades the neurodevelopmental hypothesis has come to more focus ${ }^{20,21,36,37}$. The presence of minor physical anomalies in craniofacial region of patients with schizophrenia ${ }^{10,38,39}$ points toward the common origin of craniofacial region from ectoderm and their simultaneous development in the first trimester of gestation ${ }^{38,40-42}$. Since different factors like environmental, genetic, climatic or even race may be responsible for the malformation of craniofacial features in patients with schizophrenia ${ }^{21,42,43}$, therefore it is necessary to study the relationship between these factors and their influence on the craniofacial features in patients with schizophrenia ${ }^{44}$. Our study is also based on the grounds of previous hypotheses where we try to evaluate the preliminary morphometric differences between craniofacial features in patients with schizophrenia and compare them with healthy individuals in Shiraz city.

According to our knowledge, only one study has evaluated the craniofacial features in patients with schizophrenia has been done in Iran and this will be the first to be done in Shiraz city (a city with rich cultural background and internationally acclaimed Shiraz University of Medical Sciences).

The strengths of this study include that it's the first study of this kind in Iran which could pave the way for future research in this particular field and several interesting findings will be revealed. Compared to other studies, our sample in both the groups was more which was in accordance to the suggestions made by several authors in their studies ${ }^{11,43,45}$. Schizophrenia, being a complicated disorder, the more the number of patients more will be validity of results, for example the patient sample should be more than $100^{35}$.

Unlike the studies of Buckley et al (2002) and Kelly et al (2005), ${ }^{35,45}$ and like the study done by Robin et al (2007), 11 our study included the participants from both sexes, because the development of craniofacial region after 6-9 week of gestation is dependent on sex hormones and several other factors that are specific for a particular $\operatorname{sex}^{17}$. To ensure a high credibility and accuracy two assessors were employed to take the measurements, one of who was blind to diagnosis. Unlike the study of Robin et al (2007), ${ }^{11}$ in this study height, weight and BMI were also measured in all the participants. Because the increase in weight can itself be a predisposing factor for the development of schizophrenia, or even increased BMI could also predispose a patient with schizophrenia to several other co morbidities like cardiovascular or respiratory diseases. However, studies have shown that obesity in patients with schizophrenia may be due to administration of drugs, but in contrast to this, it also could be the result of negligence to diet, patients with schizophrenia suffer from malnutrition and low body weight ${ }^{11,46-49}$. In this study, in addition to the study of Buckley et al (2002), ${ }^{35}$ we measured head height and sagittal arc length of participants.

The principle limitation of this study was the lack of more samples in both the groups that might have enhanced the accuracy of the results. The lack of previous studies of this kind in Iran that could have helped to understand the relationship between craniofacial dysmorphology and its incidence in Iran. Another limitation of this study was the linear measurements that we performed, as the development of the skull and brain is a three dimensional process ${ }^{41,50-55}$, so, it cannot be evaluated or measured well using a linear method of measurement ${ }^{17}$. Another limitation of this study was the non-uniform age among the patients and controls which can be attributed to the fact that patients with chronic schizophrenia are usually old and secondly the control group was generally the paramedical staff of a teaching hospital that was comparatively younger. Therefore the mean age of the patient group was more than that of control group and

Table 2: Cranial dimensions in individual whit schizophrenia and normal population

\begin{tabular}{|c|c|c|c|}
\hline Measurements & Groups & Mean (centimeters) & Std. deviation (centimeters) \\
\hline Head length & 1 & 18.92 & 0.91 \\
\hline Head width & 2 & 18.91 & 4.40 \\
\hline & 1 & 14.08 & 0.72 \\
\hline Head height & 2 & 13.90 & 1.45 \\
\hline & 1 & $12.70^{*}$ & 0.73 \\
\hline Axial arc length & 2 & 13.40 & 0.75 \\
\hline & 1 & 55.85 & 2.04 \\
\hline Coronal arc length & 2 & 55.71 & 1.77 \\
\hline & 1 & $35.22^{*}$ & 2.58 \\
\hline Sagittal arc length & 2 & 34.55 & 1.58 \\
\hline & 1 & $33.01^{*}$ & 1.81 \\
\hline & 2 & 32.20 & 1.41 \\
\hline
\end{tabular}


in order to omit its influence over the results, univariate analysis variance test was used.

In this study the patients with schizophrenia showed increased weight and BMI, while the height was less than the normal group. However, these findings were not statistically significant. The findings of Ainsah et al (2008) showed increased BMI and waist in patients with schizophrenia and suggested a tight control over the diet and monitoring sugar and lipid levels in patients with schizophrenia ${ }^{49}$. In this study, short stature of patients with schizophrenia was similar to the findings of Fanin et al (2006) who concluded that children of short stature are more prone to schizophrenia in youth, particularly if this short stature was present since birth ${ }^{56-58}$. The findings of Nopoulus et al (1998) also confirm the short stature of patients with schizophrenia ${ }^{59}$.

Increase in the length of coronal arc and decrease in the height of the skull in individual whit schizophrenia in our study, represent a somewhat widen in the base of skull, which may be as a result of alteration in the ossification sequences of chondrocranium and associated with expansion of middle cranial fossa, and consequently the volume of cerebral temporal lobe ${ }^{11,60,61}$. Despite, increase in the sagittal arc lenght can be as a result of early closure of sagittal suture, it is insufficient to create the troubles for development of the brain. Overall, in this study, the head circumference, head length and head width have no significant differences in individual whit schizophrenia compared to control group, and the coronal and sagittal arc lengths and cranial height are not considerably differences in the skull of patients to make changes in the cranium obviously. These results are according to the findings of Bucklly et al (2002) and Kelly et al (2005); they have demonstrated that dysmorphogenesis of the cranium and brain in schizophrenia are two separated proceedings ${ }^{35,42}$. Also, the findings of William et al (1991) confirm the lack of association between schizophrenia and abnormalities of head and face ${ }^{62}$. But Lane et al (1997) has been believed that, head and face abnormalities are associated with individual whit schizophrenia and maldevelopment of the brain ${ }^{6}$. Robin et al (2007) has been supposed that, there are much cellular and molecular relationships between head and face evolution, therefore, morphogenesis of face and head can be irrefutable evidence to show the existence of schizophrenia, even more than the brain evaluation ${ }^{11}$. In view of the fact that, the face and head morphogenesis is influenced by different factors such as age, sex, race, weight, etc.; a large number of participants are needed to find involved factors in the brain development and schizophrenia ${ }^{60}$.

On the other hand, partial or lack of differences in the skull dimensions in individual whit schizophrenia in our study, may be due to apply linear measurement technique, which, it cannot shows definite size of cranium, although, classical anthropometric techniques were used by McGrath et al (2004) and Lane et al (1997) to demonstrate morphogenesis of head and face ${ }^{3,6}$. Robin et al $(2002,2005)$ has been suggested that, this issue could be resolved by using other methods such as Laser scanning and geometric morphometric analysis, which can show all aspects and three-dimensional view of the head and face ${ }^{16,17}$. Buckley et al (2005) have demonstrated some differences of face and head morphogenesis in individual whit schizophrenia by using Laser scanning, ${ }^{63}$ unlike his previous findings, which had used the linear measurements ${ }^{35}$. In addition, absolute measuring, which are used in the most morphological studies of head and face, cannot achieve useful information compare to the proportional measuring ${ }^{64}$. Also, the outer linear measurements, due to presence of soft tissue around the skull and its thickness, can not indicate the exact volume of intracranial space and it is not extensible to the brain volume changes. But MRI shows the accurate size and definite volume of the skull and even the brain size ${ }^{35,65,66}$ and can determine the relationship between face and head and brain dysmorphogenesis ${ }^{11}$.

The findings of this study indicate that linear measurements of cranial dimensions in individual whit schizophrenia do not significantly differ from normal populations and/or there are slightly differences in some dimensions. Therefore, we suggest that; a- The MRI, Laser scanning, geometric morphometric analysis and photogrammetric, ${ }^{67,68}$ technique can be used to measure and confirm the accurate and authentic morphology of head and face and volume of interior of the cranium and pathobiological alterations of the brain in the individual whit schizophrenia. b- Considering to the diverse geographic regions and climatic conditions and various people in our vast country, it is recommend to measure the morphology of head and face of individual whit schizophrenia in different regions.

\section{References}

1. Terkelsen KG, Menikoff A. Measuring costs of schizophrenia: implications for the post-institutional era in the US. Pharmacoeconomics 1995; 8:199-222.

2. Celler JL. An historical perspective on the role of state hospitals viewed from the "revolving door". Am J Psychiatry 1992; 149: 1526-33.

3. McGrath J, Saha S, Welham J, El Saadi O, MacCauley $C$, Chant D. A systematic review of the incidence of schizophrenia: the distribution of rates and the influence of sex, urban city, migrant status and methodology. BMC Med 2004; $2: 13$.

4. WHO. Schizophrenia. Available from http://www.who.int/ mental_health/management/schizophrenia/en.

5. McGrath J. Variations in the Incidence of Schizophrenia: Data versus Dogma. Schizophr Bull 2006; 32: 195-7.

6. Lane A, Kinsella A, Murphy P, Byrne M, Kennan J, et al. The anthropometric assessment of dysmorphic features in schizophrenia as an index of its developmental origins. Psychol Med 1997; 27:1155-64.

7. O'callaghan E, Buckley P, Madigan C, Redmond O, Stack $J P$, et al. The relationship of minor physical anomalies and other putative indices of developmental disturbance in schizophrenia to abnormalities of cerebral structure of magnetic resonance imaging. Biol Psychiatry 1995; 38:516-24.

8. Gourion D, Goldberger C, Bourdel MC, Bayle FJ, Loo H, et al.Minor physical anomalies in patients with schizophrenia and their parents: prevalence and pattern of craniofacial abnormalities. Psychiatry Res 2004; 125:21-8.

9. Green MF, Satz P, Gaier DJ, Ganzell S, Kharabi F. Minor physical anomalies in schizophrenia. Schizophr Bull 1989; 15: 91-9.

10. Ismail B, Cantor-Graae E, MCNeil TF. Minor physical anomalies in schizophrenia patients and their siblings. Am J Psychiatry 1998; 155:1695-1702. 
11. Hennessy RJ, Baldwin PA, Browne DJ, Kinsella A, Waddington JL. Three-Dimensional Laser Surface Imaging and Geometric Morphometrics Resolve Frontonasal Dysmorphology in Schizophrenia. Biol Psychiatry 2007; 61:1187-94.

12. Smith DW. Recognizable patterns of human malformation (4th ed). Philadelphia:WB Saunders, 1988.

13. Marcucio RS, Cordero DR, Hu D, Helms JA. Molecular interactions coordinating the development of the forebrain and face. Dev Biol 2005; 284: 48-61.

14. Nopulos P, Berg S, Canady J, Richman L, Van Demark D, et al. Structural brain abnormalities in adult male with clefts of the lip and/or palate. Genet Med 2002; 4:1-9.

15. Nopulos P, Berg S, Canady J, Van Demark D, Richman L, et al. Cognitive dysfunction in adult male with non syndromic clefts of the lip and/or palate. Neurosychologia 2002; 40: 2178-84.

16. Hennessy RJ, Kinsella A, Waddington JL. 3D Laser surface scanning and geometric morphometric analysis of craniofacial shape as an index of cerebro-craniofacial morphogenesis: Initial Application to Sexual Dimorphism. Biol Psychiatry 2002; 5: 507-14.

17. Hennessy RJ, McLearie S, Kinsella A, Waddington JL. Facial surface analysis by $3 D$ laser scanning and geometric morphometrics in relation to sexual dimorphism in cerebral-craniofacial morphogenesis and cognitive function. J Anat 2005; 207: 283-95.

18. Murphy KC, Owen MJ. Velo-cardio-facial syndrome: a model for understanding the genetics and pathogenesis of schizophrenia. Br J Psychiatry 2001; 179: 397-402.

19. Lane A, Larkin C,Waddington JL, O'Callaghan. Dysmorphic features and schizophrenia. In:Waddington JL, Buckley PF, editors. The Neurodevelopmental Basis of Schizophrenia. Georgetown, Texas: Landes, 1996; P79-93.

20. Gupta S, Kulhara P. What is schizophrenia: $A$ neurodevelopmental or neurodegenerative disorder or a combination of both? $A$ critical analysis. Indian $J$. Psychiatry 2010; 52: 21-7.

21. Holtam C. The neurodevelopmental hypothesis of schizophrenia. Available from www. Priory .com/psych/ neuorodev.htn 2000.

22. Jakob H, Beckmann H. Prenatal developmental disturbances in the limbic allocortex in schizophrenics. $J$ Neural Transm 1986; 65: 303-26.

23. Arnold SE, Hyman BT, Van Hoesen GW, Damasio AR. Some cytoarchitectural abnormalities of the entorhinal cortex in schizophrenia. Arch Gen Psychiatry 1991; 48: 625-32.

24. Benes FM, MCSparren J, Bird ED, SanGiovanni JP,Vincent SL. Deficits in small interneurons in prefrontal and cingulated cortices of schizophrenic and schizoaffective patients. Arch Gen Psychiatry 1991; 48: 990-1001.

25. Akbarian S, Bunney WE Jr, Potkin SG, Wigal SB, Hagman $J O$, et al. Altered distribution of nicotamide-adenine dinucleotide phosphate-diaphorase cells in frontal lobe schizophrenics implies disturbances of cortical development. Arch Gen Psychiatry 1993; 50: 169-77.

26. Zaidel DW, Esiri MM, Harrison PJ. The hippocampus in schizophrenia: literalized increase in neuronal density and altered cytoarchitectural asymmetry. Psychol Med 1997; 27: 703-13.

27. Bertolino A, Nawroz S, Mattay VS, Barnett AS, Duyn JH, et al. Regionally specific pattern of neurochemical pathology in schizophrenia as assessed by multi-slice proton magnetic resonance spectroscopic imaging. Am J Psychiatry 1996; 153: 1554-63.

28. Kasparek T, Marecek R, Schwarz D, Prikryl R, Vanícek J, et al. Source-Based morphometry of gray matter volume in men with first-episode schizophrenia. Hum Brain Mapp 2010; 3: 300-10.

29. Barbeau D, Liang JJ, Robitalille Y, Quirion R, Srivastava $L K$. Decreased expression of the embryonic form of the neural cells adhesion molecule in schizophrenic brains. Proc Natl Acad Sci USA 1995; 92: 2785-9.

30. Perrone-Bizzozero NI, Sower AC, Bird ED, Benowitz LI, Ivins KJ, et al. Levels of growth associated proteins GAP43 are selective increased in association cortices in schizophrenia. Proc Natl Acad Sci USA 1996; 93: 14182-7.

31. Jakob H, Beckmann H. Gross and histological criteria for developmental disorders in brains of schizophrenics. $J R$ Soc Med 1989; 82: 466-469.

32. Armstrong E, Schleicher A, Omran H, Curtis M, Zilles $K$. The ontogeny of human gyrification. Cereb Cortex 1995; 5: 56-63.

33. Lobato MI, Belmonte-de-Abreu P, Knijnik D, Teruchkin $B$, Ghisolfi $E$, et al. Neurodevelopmental risk factors in schizophrenia. Braz J Med Biol Res 2001; 34:155-63.

34. Gelowitz DL, Rakic P, Patricia S. Goldman-Rakic, Selemon LD. Craniofacial dysmorphogenesis in fetally irradiated nonhuman primates: Implications for the neurodevelopmental hypothesis of schizophrenia. Biol Psychiatry 2002; 52: 716-20.

35. Buckley PF, Friedman Lee, Jesberger JA, Schulz C, Jaskiw G. Head size and schizophrenia. Schizophr Res 2002; 55 . 99-104.

36. Pantelis C, Yücel M, Wood SJ, MCGorry PD, Velakoulis D. Early and late neurodevelopmental disturbances in schizophrenia and their functional consequences. Aust $N$ Z J Psychiatry 2003; 37: 399-406.

37. McGrath JJ, Féron FP, Burne TH, Mackay-Sim A, Eyles DW. The neurodevelopmental hypothesis of schizophrenia: a review of recent developments. Ann Med 2003; 35: 86-93.

38. Cannon $M$, Dean $K$, Jones PB. Early environmental risk factors for schizophrenia. In: Keshavan, M.S., Kennedy, J.L., Murray, R.M.(Eds.), Neurodevelopment and Schizophrenia. Cambridge: Cambridge University Press, 2004, 191-209.

39. Green MF, Satz P, Chrlstenson C. Minor physical anomalies in schizophrenia patients, bipolar patients and their siblings. Schizophr Bull 1994; 20: 433-40.

40. Buckley PF. The clinical stigmata of aberrant neurodevelopment in schizophrenia. J Nerv Ment Dis 1998; 186: 79-86.

41. Waddington JL, Lane A, Scully P, Meagherb D, Quinnb $J$, et al. Early cerebro-craniofacial dysmorphogenesis in schizophrenia: a lifetime trajectory model from neurodevelopmental basis to "neuroprogressive" process. J Psychiatr Res 1999; 33: 477-89. 
42. Kelly BD, Lane A, Agartz I, Henriksson KM, McNeil TF. Craniofacial dysmorphology in Swedish schizophrenia patients. Acta Psychiatr Scand 2005;1 11:202-7.

43. Compton MT, Brudno J, Kryda AD, Bollini AM, Walker EF. Facial measurement differences between patients with schizophrenia and non-psychiatric controls. Schizophr Res 2007; 93: 245-52.

44. Kolar JC. Methods in anthropometric studies. Cleft Palate Craniofac J. 1993; 30: 429-31.

45. Kelly BD, McNeil TF, Lane A, Henriksson KM, Kinsella A, et al. Is craniofacial dysmorpholgy correlated with structural brain anomalies in schizophrenia? Schizophr Res 2005;80: 349-55.

46. Ananth J, Venkatesh R, Burgoyne K, Gadasalli R, Binford R, Gunatilake S. Atypical antipsychotic induced weight gain: pathophysiology and management. Ann Clin Psychiatry 2004; 16: 75-85.

47. Jin H, Meyer JM, Jeste DV. Atypical antipsychotics and glucose dysregulation: A systematic review. Schizophr Res 2004;71: 195-212.

48. Wirshing DA. Schizophrenia and obesity: Impact of antipsychotic medications. J Clin Psychiatry 2004; 65:1326.

49. Ainsah O, Salmi R, Osman CB, Shamsul AS. Relationship between antipsychotic medication and anthropometric measurements in patients with schizophrenia attending in psychiatric clinic in Malaysia. Hong Kong J Psychiatry 2008; 18: 23-7.

50. Baldwin P, Hennessy RJ, Morgan MG, Quinn JF, Scully PJ, et al. Controversies in schizophrenia research: the 'continuum' challenge, heterogeneity vs homogeneity, and lifetime developmental-'neuroprogressive' trajectory. In: Gattaz W, Haffner H, editors. Search for the Causes of Schizophrenia. Darmstadt: Steinkopff, 2004, p. 394- 409.

51. Diewert VM, Lozanoff $S$. A morphometric analysis of human embryonic craniofacial growth in the median plane during primary palate formation.J Craniofac Genet Dev Biol 1993;13: 147-61.

52. Diewert VM, Lozanoff S. Growth and morphogenesis of the human embryonic midface during primary palate formation analyzed in frontal sections. J Craniofac Genet Dev Biol 1993; 13: 162-83.

53. Diewert VM, Lozanoff S, Choy V. Computer reconstructions of human embryonic craniofacial morphology showing changes in relations between the face and brain during primary palate formation. J Craniofac Genet Dev Biol 1993;13: 193-201.

54. Schneider RA, Hu D, Rubenstein JLR, Maden M, Helms $J A$. Local retinoid signaling coordinates forebrain and facial morphogenesis by maintaining FGF8 and SHH. Development 2001;128: 2755-67.

55. Waddington JL, Lane A, Larkin C, O'Callaghan E. The neurodevelopmental basis of schizophrenia: clinical clues from cerebro-craniofacial dysmorphogenesis, and the roots of a lifetime trajectory of disease. Biol Psychiatry 1999;46: 31-9.

56. Rasmussen F. Paternal age, size at birth, and size in young adulthood-risk factors for schizophrenia. Eur JEndocrinol 2006; 155: 65-9.

57. Sipos A, Rasmussen F, Harrison G, Tynelius P, Lewis G, et al. Paternal age and schizophrenia: a population based cohort study. Br Med J 2004; 329: 1070-4.

58. Gunnell D, Harrison G, Whitley E, Lewis G, Tynelius $P$, et al. The association of fetal and childhood growth with risk of schizophrenia. Cohort study of 720000 Swedish men and women. Schizophr Res 2005; 79: 315-22.

59. Nopoulos P, Flaum M, Arndt S, Andreasen N. Morphometry in schizophrenia revisited: height and its relationship to pre-morbid function. Psychol Med 1998; 28: 655-63.

60. Donovan-Lepore AM, Jaeger J, Czobor P, Abdelmessih S, Berns SM. Quantitative craniofacial anomalies in a racially mixed schizophrenia sample. Biol Psychiatry 2006; 59: 349-53.

61. McGrath J, El-Saadi O, Grim V, Cardy S, Chapple B, Chant D, et al. Minor physical anomalies and quantitative measures of the head and face in patients with psychosis. Arch Gen Psychiatry 2002; 59: 458-64.

62. Grove WM, Lebow BS, Medus C. Head Size in Relation to Schizophrenia and Schizotypy. Schizophr Bull 1991;17: 157-61.

63. Buckley PF, Dean D, Bookstein FL, Han S, Yerukhimovich $M$, et al. $A$ Three-dimensional morphometric study of craniofacial shape in schizophrenia. Am J Psychiatry 2005; 16: 606-8.

64. Farkas LG, Munro IR. Anthropopmetric facial proportions in medicine. Springfield, IL: Charles C. Thomas, 1987, $p$. 166-308.

65. Henriksson KM, Kelly BD, Lane A, Hult R, McNeil TF, et al. A morphometric magnetic resonance method for measuring cranial, facial and brain characteristics for application to schizophrenia: Part 1. Psychiatry Res 2006; 147: 173-86.

66. Henriksson $K M$, Wickstrom $K$, Maltesson $N$, Ericsson $A$, Karlsson J, et al. A pilot study of facial, cranial and brain MRI morphometry in men with schizophrenia: Part 2. Psychiatry Res 2006; 147: 187-95.

67. Wong JY, Oh AK, Ohta E, Hunt AT, Rogers GF, Mulliken JB, et al. Validity and Reliability of Craniofacial Anthropometric Measurement of $3 D$ Digital Photogrammetric Images. Cleft Palate Craniofac J 2008; 45: 232-9.

68. Franke-Gromberg C, Schüler G, Hermanussen M, Scheffler C. Digital 2D-photogrammetry and direct anthropometry-a comparing study on test accomplishment and measurement data. Anthropol Anz 2010; 68: 11-20. 